\title{
Laryngeal Fracture due to Blunt Trauma Presenting with Pneumothorax and Pneumomediastinum
}

\author{
Adnan Narcı Didem Baskın Embleton Abdullah Ayçiçek Fatih Yücedağ \\ Salih Çetinkurşun \\ Departments of Pediatric Surgery and Otorhinolaryngology, Afyon Kocatepe University Medical Faculty, \\ Afyon, Turkey
}

\section{Key Words}

Laryngeal trauma - Pneumomediastinum • Facial fractures • Child

\begin{abstract}
Aim: Injuries due to traffic accidents are frequent in childhood, and they have high mortality and morbidity. Laryngeal injury due to a traffic accident is a rare pathology and might be missed if not suspected. Here we present a laryngeal fracture in a child after a blunt chest trauma during a traffic accident that presented with pneumomediastinum and pneumothorax. Case: A 14-year-old girl was referred for pneumomediastinum. Her physical examination was normal except subcutaneous emphysema, edema and tenderness in the cervical area, hoarseness, facial and extremity abrasions and ecchymoses. Chest tomography revealed pneumothorax and pneumomediastinum, and cranial tomography revealed maxillofacial fractures. Upper airway damage was suspected, flexible endoscopy revealed right vocal cord paralysis and cervical tomography revealed thyroid cartilage fracture. The fracture was repaired and tracheotomy was performed. She was discharged on postoperative day 6. Facial fractures were repaired in another center. Tracheotomy was removed on postoperative day 20 . Her hoarseness, al-
\end{abstract}

though decreased, still persists. Conclusion: Pneumomediastinum is a rare result of a laryngeal fracture and if not suspected, the fracture can easily be missed. It should be kept in mind after blunt cervical trauma with pneumomediastinum and/or pneumothorax. Direct endoscopy and cervical tomography may be necessary for the differential diagnosis.

Copyright $\odot 2011$ S. Karger AG, Basel

Laryngeal trauma is rare in childhood. Varying incidences (from 1:30,000 to 1:137,000) were reported in different patient series. It is more frequent in boys than girls (77 vs. 33\%). Although rare, its consequences may be mortal. Symptoms may be subtle initially $[1,2]$. This leads to delayed diagnosis and increased morbidity and mortality. Aspiration, phonation and/or respiratory problems are common [3].

\section{Case Presentation}

A 14-year-old girl was referred for pneumomediastinum after a motor vehicle occupant injury. Her physical examination was normal except subcutaneous emphysema, edema and tenderness in the cervical area, hoarseness, facial and extremity abrasions

\section{KARGER}

Fax +41613061234

E-Mail karger@karger.ch

www.karger.com
(C) 2011 S. Karger AG, Basel

0301-1569/11/0735-0246\$38.00/0

Accessible online at:

www.karger.com/orl
Adnan Narc1, Assoc. Prof.

Afyon Kocatepe Universitesi Tip Fakültesi

Cocuk Cerrahisi AD

TR-03200 Afyon (Turkey)

Tel. +90272 246 3333,E-Mail adnannarci@yahoo.com 

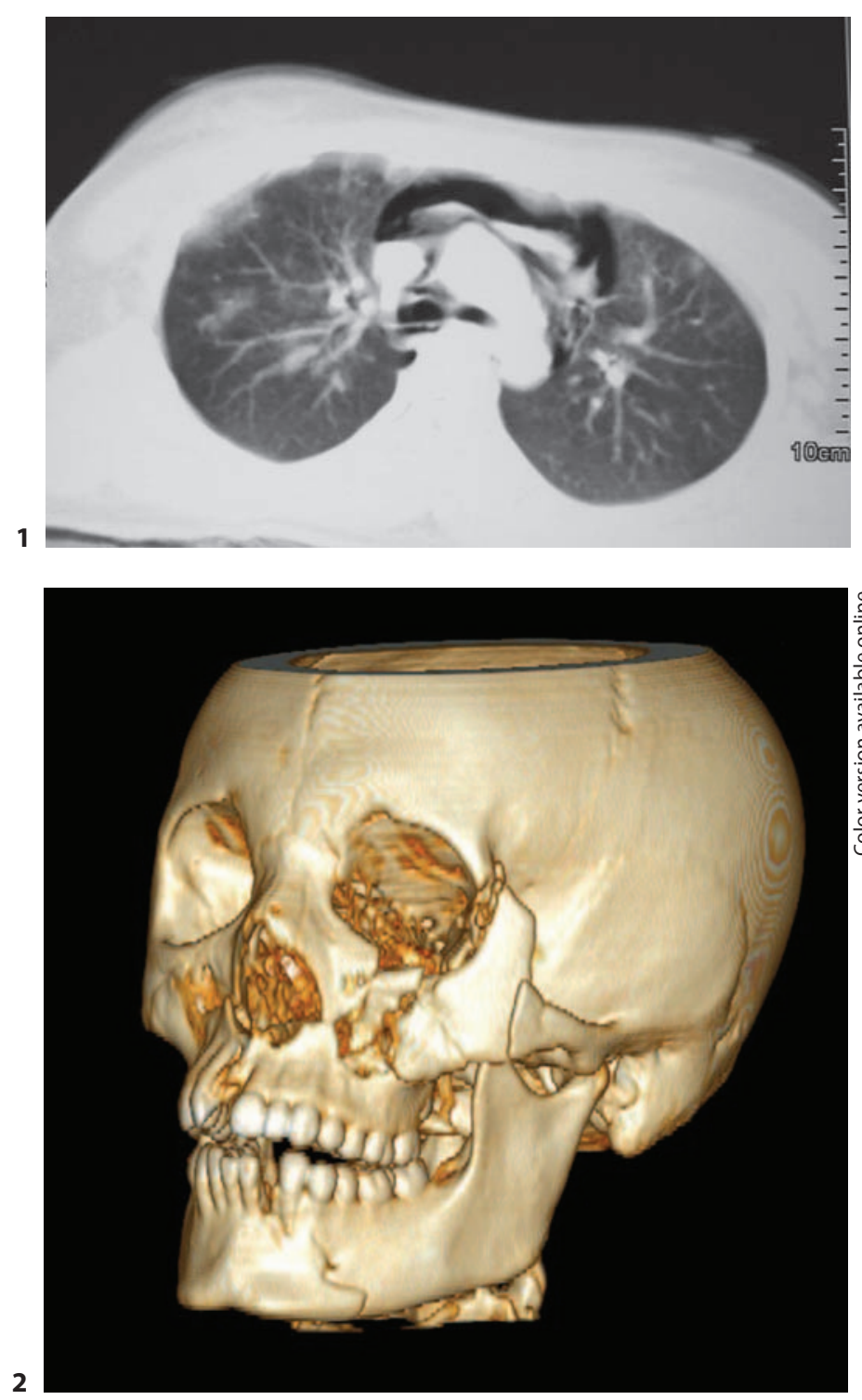

Fig. 1. Pneumothorax, pneumomediastinum and lung contusion are seen in chest tomography.

Fig. 2. Maxillofacial fractures are seen in reconstructive cranial tomography.

and ecchymoses. Chest tomography revealed lung contusion, pneumothorax and pneumomediastinum, and cranial tomography revealed maxillofacial fractures (fig. 1,2). Although pneumothorax was resolved, mediastinal air was increased during her hospital stay. Otorhinolaryngology consultation was requested. Right vocal cord paralysis was seen with flexible endoscopy. Cervical tomography revealed thyroid cartilage fracture. Neck exploration was performed. During surgery, thyroid cartilage was

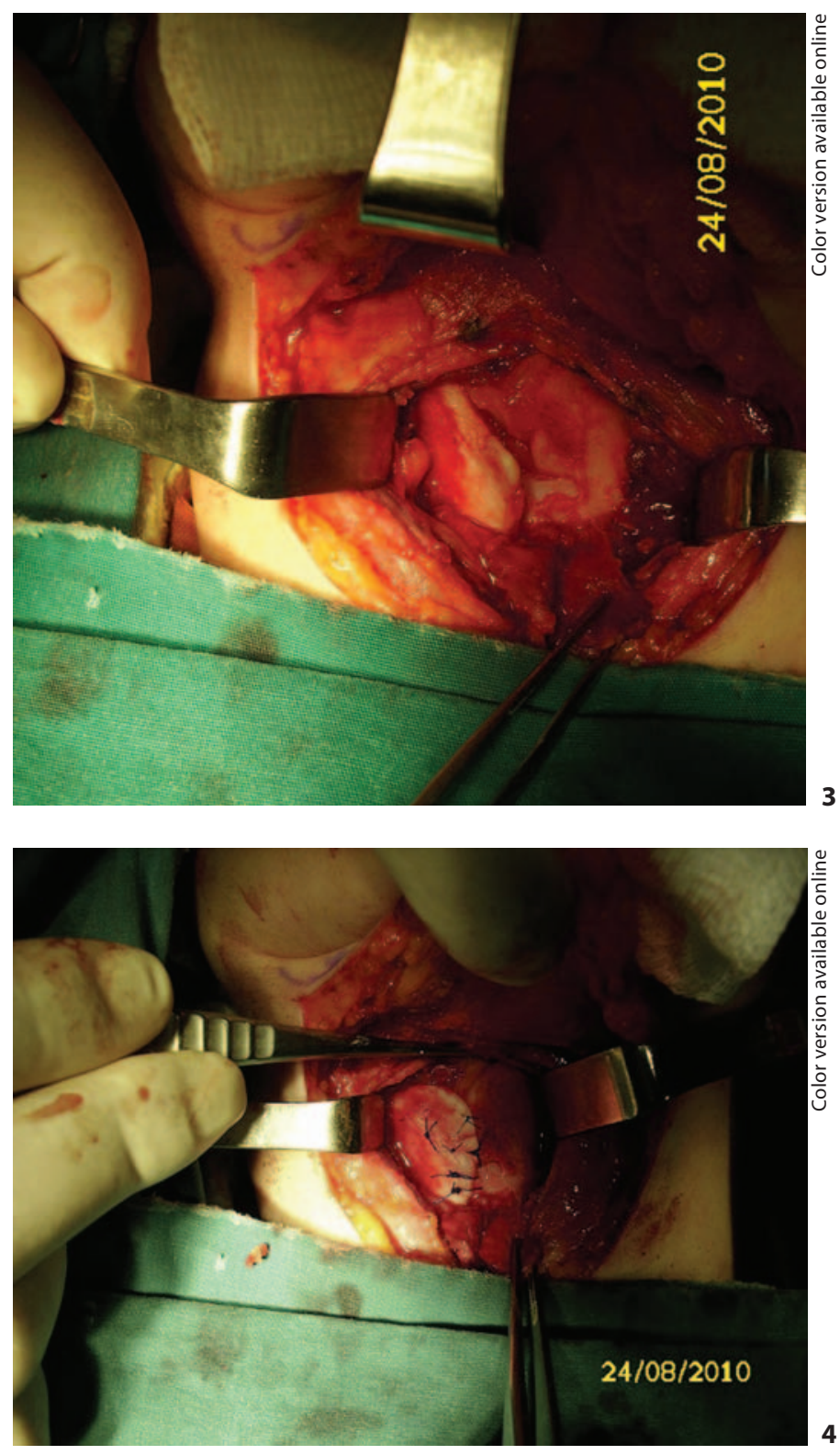

Fig. 3. Fractured thyroid cartilage.

Fig. 4. Repaired thyroid cartilage after surgery.

found fractured in the midline, and the superior thyroid lamina was displaced cranially. There was a horizontal cut on the left lamina (fig. 3). The fracture was repaired with 4-0 prolene, and tracheostomy was performed by otorhinolaryngology surgeons (fig. 4). She was discharged on postoperative day 6. Facial fractures were repaired in another center. Tracheostomy was removed on postoperative day 20. Her hoarseness, although decreased, still persists. 


\section{Discussion}

Maxillofacial fractures with simultaneous laryngeal fracture as a result of blunt trauma are rare pathologies with potential life-threatening results. They can frequently be found together so if maxillofacial trauma is seen, laryngeal injury should be sought.

Presenting physical findings of laryngeal injury are edema, tenderness to palpation, dysphonia, subcutaneous emphysema and neck pain [4]. These symptoms are not pathognomonic, and they were all present in our patient as well. Recognition and treatment of this problem require a high index of suspicion. About $37 \%$ of the patients in a reported series had delayed diagnosis [5]. Our patient was diagnosed on day 4 after the accident. The cause of the delay was suspected lung injury due to the accident as the cause of pneumothorax. Persistence of pneumomediastinum after the disappearance of pneumothorax led to the suspicion of a laceration in the upper airways. Diagnosis was supported with the use of flexible endoscopy and cervical tomography which are not standard diagnostic tools in the initial evaluation of childhood traumas [6]. It was found that pneumomediastinum resulted from the airway dissection through fractured thyroidal cartilages with negative pressure of the thorax.

Treatment of laryngeal injury is surgical. Primary repair is usually preferred, depending on the severity of the injury. Early (within $24 \mathrm{~h}$ ) versus late (3-5 days after trauma) repair is subject to debate $[7,8]$. Early repair is advocated especially in patients with simultaneous maxillofacial fractures [9]. Because these are rare pathologies, extensive experience is lacking and the effect of timing of repair on airways, phonation and deglutition is not clear, especially in children. Delayed diagnosis resulted in delayed repair in our patient. Her maxillofacial fractures were repaired after laryngeal repair in another center.

It can be concluded that laryngeal fracture due to blunt trauma is a rare pathology that usually goes with a delayed diagnosis. As a consequence, it may have a high morbidity and mortality. A good history taking that reveals direct trauma to the anterior part of the neck with pneumomediastinum and subcutaneous emphysema should lead us to the suspicion of the upper airway injury such as laryngeal laceration. Presence of maxillofacial injury should also raise the suspicion of laryngeal injury.

\section{References}

1 Schaefer SD: The acute management of external laryngeal trauma. Arch Otolaryngol Head Neck Surg 1992;118:598-604.

$\checkmark 2$ Jewett BS, Shockley WW, Rutledge R: Externallaryngeal trauma analysis of 392 patients. Arch Otolaryngol Head Neck Surg 1999;125: 877-880.

$\checkmark 3$ Assimakopoulos D, Tsirves G: Blunt trauma of the larynx and pneumomediastinum. J Trauma 2008;65:1340-1345.
4 Shockley WW: Laryngeal trauma; in Shockley WW, Pillsbury HC (eds): The Neck - Diagnosis and Surgery. St Louis, Mosby, 1993, pp 189-208.

5 Thompson JN, Gibson B, Kohut RI: Airway obstruction in LeFort fractures. Laryngoscope 1987;97:275-279.

6 Kuttenberger JJ, Hardt N, Schlegel C: Diagnosis and initial management of laryngotracheal injuries associated with facial fractures. J Craniomaxillofac Surg 2004;32:8084
7 Schaefer SD: The treatment of acute external laryngeal injuries. 'State of the art'. Arch Otolaryngol Head Neck Surg 1991;117:3539.

8 Olson NR: Surgical treatment of acute blunt laryngeal injuries. Ann Otol Rhinol Laryngol 1978;87:716-721.

9 Cantrell RW: Laryngeal trauma reviewed. Commentary on: Leopold DA: Laryngeal trauma - a historical comparison of treatment methods. Arch Otolaryngol 1983;109: 112 . 